\title{
Application of the Adaptive Statistics Method for Reanalysis of the Black Sea Fields Including Assimilation of the Temperature and Salinity Pseudo-Measurements in the Model
}

\author{
G. K. Korotaev, V. V. Knysh*, P. N. Lishaev, S. G. Demyshev \\ Marine Hydrophysical Institute, Russian Academy of Sciences, Sevastopol, Russian Federation \\ *e-mail: vaknysh@yandex.ru
}

\begin{abstract}
To assimilate the thermohaline parameters' pseudo-measurements in the model, applied is the method of adaptive statistics, the characteristic feature of which consists in adjusting the three-dimensional errors' dispersions of the temperature and salinity forecast to the water circulation in the basin. The three-dimensional fields of the temperature and salinity pseudo-measurements are reconstructed in the 100-500 m layer based on the altimetry data and the Argo buoys' limited measurements. The method is approved and validated by comparing the sea fields reconstructed in the reanalysis for 2012 with the Argo measurements. It is revealed that on the horizons 100, 113 and $125 \mathrm{~m}$, the dispersions of differences (residuals) between the temperature pseudo-measurements and its model values somewhat exceed the model dispersion; whereas on the horizons within the 150-500 m layer, they are smaller. The daily standard deviation of the model level (relative to that reconstructed using the altimetry data) is smaller than the deviation calculated in the forecast; and during the March - September period, it is lower than the standard deviation resulted from the pseudo-measurements' assimilation by the simplified method. Resolution of the mesoscale vortices in the currents' fields is higher in case the method of adaptive statistics is used.
\end{abstract}

Keywords: adaptive statistics, dispersion of forecast errors, pseudo-measurements, validation, dispersion of residuals.

Acknowledgments. The work was carried out within the framework of the state order on the topic No. 0827-2014-0011 "Studies of the regularities of the marine environment condition changes on the basis of operational observations and data from the system of now cast, prognosis and reanalysis of the state of marine areas" ("Operational Oceanography" code), and with partial support of RFBR, grant No. 16-05-00621.

For citation: Korotaev, G.K., Knysh, V.V., Lishaev, P.N. and Demyshev, S.G., 2018. Application of the Adaptive Statistics Method for Reanalysis of the Black Sea Fields Including Assimilation of the Temperature and Salinity Pseudo-measurements in the Model. Physical Oceanography, [e-journal] 25(1), pp. 36-51. doi:10.22449/1573-160X-2018-1-36-51

DOI: $10.22449 / 1573-160 X-2018-1-36-51$

(C) 2018, G. K. Korotaev, V. V. Knysh, P. N. Lishaev, S. G. Demyshev

(C) 2018, Physical Oceanography

Introduction. The methods of the measurement data assimilation applied in the hydrodynamic ocean models for solving the problems of retrospective analysis provide realistic reproduction of the oceanographic fields. At present, the most commonly used methods include the variational assimilation of observational data [1-3] and the Kalman filter [4, 5], namely, two its varieties for calculating the matrices of the forecast errors' dispersions: the simplified method [6-8] and the one based on the ensemble of realizations [6, 9 and 10]. The Kalman ensemble filter requires high power computer installation and does not always guarantee obtaining of optimal weighting coefficients [10].

The algorithm of the Kalman discrete-continuous filter [4 and 11] implies that during the intervals between observations, the state vector components and the er- 
ror covariations' matrix are forecasted using the matrix operator in the hydrodynamic model by the moment the immediate observation data are received. At the observation moments, the prognostic values of the state vector components are corrected by the weighted differences between the observations and the prognostic state vector components interpolated from the grid nodes to the observation points. Besides, the error covariation matrix is also corrected [11 and 12]. The simplified covariation function of the temperature (salinity) forecast errors was applied in [13] to develop the method of adaptive statistics used for reproducing climatic circulation. This method was also used in [14] to carry out a retrospective analysis of the Black Sea fields. Note that in [13] the characteristic (typical) dispersions of the temperature and salinity forecast errors depended on the vertical coordinate, were calculated by the single-type differential equations and applied at assimilating thermohaline climate fields in the model. In contrast to the indicated paper, in [14] the three-dimensional typical dispersions of the forecast errors were assessed that permitted to reconstruct the sea hydrophysical fields in the reanalysis for 19851993 at the model resolution $5 \times 5 \mathrm{~km}$. However, the method for estimating typical dispersions applied to the reanalysis from 1993 up to present with lack of temperature and salinity measurements by the Argo buoys during this period taken into account, as well as the tool for taking these estimates into account in the differential equations need to be specified.

The purpose of the research was to carry our special numerical experiments (including analysis of the results) aimed at perfecting the adaptive statistics method, its subsequent application in reanalysis of the Black Sea fields and the model assimilation of the originally reconstructed three-dimensional temperature and salinity fields in the 100-500 $\mathrm{m}$ layer $\mathrm{m}$ in the deep-sea part of the basin.

Basic relations of the Kalman filter and the method of adaptive statistics. Let us pay attention below to the procedure of assimilation in the model of the temperature and salinity observation data. The data are received at the discrete points of time ( $t_{l}=l \Delta t_{\mathrm{obs}}$, where $\Delta t_{\mathrm{obs}}$ are the periods; $l=1,2, \ldots$ ) and at $N$ points of space. The formulas of the temperature optimal estimate correction $\widehat{T}\left(\vec{x}, t_{l}\right)$ (in the terms of the mean square criterion) and the covariance functions of the temperature estimates' errors $P_{T}\left(\vec{x}, \vec{x}^{\prime}, t_{l}\right)=E\left[\delta T\left(\vec{x}, t_{l}\right) \cdot \delta T\left(\vec{x}^{\prime}, t_{l}\right)\right]$ ( $E$ is the averaging operator) at these moments in an explicit form are as follows:

$$
\begin{gathered}
\widehat{T}\left(\vec{x}, t_{l}^{* *}\right)=\widehat{T}\left(\vec{x}, t_{l}^{*}\right)+\sum_{r=1}^{N}\left[\Delta_{r}^{T}\left(\vec{x}, t_{l}^{*}\right) \delta T\left(\vec{x}_{r}, t_{l}^{*}\right)\right], \\
P_{T}\left(\vec{x}, \vec{x}^{\prime}, t_{l}^{* *}\right)=P_{T}\left(\vec{x}, \vec{x}^{\prime}, t_{l}^{*}\right)-\sum_{r=1}^{N} \Delta_{r}^{T}\left(\vec{x}, t_{l}^{*}\right) P_{T}\left(\vec{x}_{r}, \vec{x}^{\prime}, t_{l}^{*}\right),
\end{gathered}
$$

In expressions (1)-(2)

$$
\begin{gathered}
\vec{\Delta}^{T}\left(\vec{x}, t_{l}^{*}\right)=\left\|\Delta_{1}^{T}\left(\vec{x}, t_{l}^{*}\right), \Delta_{2}^{T}\left(\vec{x}, t_{l}^{*}\right), \ldots, \Delta_{N}^{T}\left(x, t_{l}^{*}\right)\right\|^{\prime}= \\
=\left[P_{T}\left(\vec{x}_{r}, \vec{x}_{p}, t_{l}^{*}\right)+R_{T}\left(\vec{x}_{r}, \vec{x}_{p}, t_{l}\right)\right]^{-1} \times P_{T}\left(\vec{x}, \vec{x}_{r}, t_{l}^{*}\right), r, p=1,2, \ldots, N, \\
\delta T\left(\vec{x}_{r}, t_{l}^{*}\right)=T\left(\vec{x}_{r}, t_{l}\right)-\widehat{T}\left(\vec{x}_{r}, t_{l}^{*}\right) .
\end{gathered}
$$

PHYSICAL OCEANOGRAPHY VOL. 25, ISS. 1 (2018) 
In formulas (1)-(4), the signs “*” and “**” indicate the values of the functions before and after correction, respectively; the apostrophe sign denotes the vector transportation. The square brackets with the superscript -1 in formula (3) identify the inverse matrix multiplied by the column-vector $P_{T}\left(\vec{x}, \vec{x}_{r}, t_{l}^{*}\right)$, the elements of which are the covariance functions of the temperature estimates' errors $P_{T}\left(\vec{x}_{r}, \vec{x}_{p}, t_{l}^{*}\right)$ and the covariance functions of the temperature $T\left(\vec{x}_{r}, t_{l}\right)$ measurements' $R_{T}\left(\vec{x}_{r}, \vec{x}_{p}, t_{l}\right)$ errors. The horizontal components of the currents' velocity vector are not corrected directly by the measurements.

The main difficulty in implementing the Kalman filter consists in calculating the covariance functions of the estimates' errors. In accordance with [12, p. 182], let us represent these functions in the following form:

$$
P_{T}\left(\vec{x}, \vec{x}^{\prime}, t\right) \approx \sigma_{T}(\vec{x}, t) \sigma_{T}\left(\vec{x}^{\prime}, t\right) P_{T}^{\mathrm{H}}\left(\left|x-x^{\prime}\right|,\left|y-y^{\prime}\right|, z\right) .
$$

In expression (5), $\sigma_{T}(\cdot)$ is the root-mean-square (RMS) of the temperature estimates' errors; $P_{T}^{\mathrm{H}}\left(\left|x-x^{\prime}\right|,\left|y-y^{\prime}\right|, z\right)$ is the normalized autocorrelation function of the errors' fields depending on the distance between the points in the grid region of the numerical model.

To assimilate the reproduced temperature and salinity three-dimensional fields in the model, applied is the original procedure for synthesizing the limited measurement data of the Argo buoys and the anomalies of the altimetry level [15]. Due to this procedure, the three-dimensional fields of the temperature and salinity pseudo-measurements for 1993-2014 have been reconstructed in all the points of the model grid in the 100-500 m layer of the deep-sea region limited by the isobath $500 \mathrm{~m}$. RMS of the reconstructed fields' are also estimated by means of their comparison with the measurements. The temperature and salinity pseudo-measurements are proposed to be considered in the first approximation as independent, and, in such a case, the correlations (5) in each point of the grid are reduced to dispersions.

Dispersions of the temperature and salinity estimates' errors were calculated through numerical solution of the corresponding differential equations which are derived using the equations of heat and salt transfer-diffusion. The method of obtaining differential equations of dispersions of the temperature and salinity estimates' errors is more completely described in [12]. The differential equation of the dispersion of the temperature estimates' errors is given in the following form as an example (the functions' arguments are omitted):

$$
\frac{\partial \sigma_{T}^{2}}{\partial t}+\frac{\partial \sigma_{T}^{2} u}{\partial x}+\frac{\partial \sigma_{T}^{2} v}{\partial y}+\frac{\partial \sigma_{T}^{2} w}{\partial z}=\frac{\partial}{\partial z} k^{T} \frac{\partial \sigma_{T}^{2}}{\partial z}+k_{\mathrm{H}} \Delta \sigma_{T}^{2}+\frac{1}{\mathrm{REL}}\left(\sigma_{*_{T}}^{2}-\sigma_{T}^{2}\right) .
$$

The equation for the dispersion of the salinity estimates' errors $\sigma_{S}^{2}(\vec{x}, t)$ is of the same form. The single-type equations are the approximated ones as in the deduced equations neglected are the mutual dispersions of the temperature (salinity) estimates' errors and the velocity vector components multiplied by the derivatives of the temperature (salinity) estimates over the axes $x, y$ and $z$, and also the mean squared derivatives of the temperature (salinity) estimates' errors. In the right-hand side of equation (6) $k^{T}, k_{\mathrm{H}}$ are the vertical and horizontal coefficients of the turbulent exchange; $\Delta$ is the Laplace operator; the third summand is the source taking into 38

PHYSICAL OCEANOGRAPHY VOL. 25, ISS. 1 (2018) 
account seasonal variability of typical dispersions of the temperature $\sigma_{*_{T}}^{2}\left(\vec{x}, t_{l}\right)$ (salinity $\left.\sigma_{* S}^{2}\left(\vec{x}, t_{l}\right)\right)$ forecast errors in the Black Sea.

With the above-mentioned features of the reconstructed on the model grid temperature pseudo-measurements taken into account, ratio (1) in the first approximation can be represented in the following form

$$
\widehat{T}\left(\vec{x}, t_{l}^{* *}\right)=\widehat{T}\left(\vec{x}, t_{l}^{*}\right)+\frac{\sigma_{T}^{2}\left(\vec{x}, t_{l}^{*}\right)}{\left[\sigma_{T}^{2}\left(\vec{x}, t_{l}^{*}\right)+\sigma_{\mathrm{ow} T}^{2}\left(\vec{x}, t_{l}\right)\right]}\left[T^{\mathrm{obs}}\left(\vec{x}, t_{l}^{*}\right)-\widehat{T}\left(\vec{x}, t_{l}^{*}\right)\right],
$$

where $T^{\text {obs }}\left(\vec{x}, t_{l}^{*}\right)$ are the reconstructed three-dimensional fields of the temperature pseudo-measurements at a point of time $t_{l} ; \sigma_{\text {oшT }}^{2}\left(\vec{x}, t_{l}\right)$ is the dispersions of reconstruction errors. Being corrected by formula (7), the temperature varies abruptly. In order to get smooth change of the hydrophysical fields, while solving the model equations numerically, the source of the following form (hereinafter the "cap" over the model temperature $T\left(\vec{x}, t_{l}\right)$ will not be used) was included in the right-hand sides of the heat transfer-diffusion equations:

$$
Q_{T}\left(\vec{x}, t_{l}\right)=\frac{\sigma_{T}^{2}\left(\vec{x}, t_{l}^{*}\right)}{\operatorname{REL} 1\left[\sigma_{T}^{2}\left(\vec{x}, t_{l}^{*}\right)+\sigma_{\mathrm{om} T}^{2}\left(\vec{x}, t_{l}^{*}\right)\right]}\left[T^{\mathrm{obs}}\left(\vec{x}, t_{l}\right)-T\left(\vec{x}, t_{l}\right)\right] .
$$

After pseudo-measurements are assimilated in the considered approximation, the dispersions of the temperature estimate (forecast) errors are corrected by the formula

$$
\sigma_{T}^{2}\left(\vec{x}, t_{l}^{* *}\right)=\sigma_{T}^{2}\left(\vec{x}, t_{l}^{*}\right)-\frac{\sigma_{T}^{2}\left(\vec{x}, t_{l}^{*}\right) \sigma_{T}^{2}\left(\vec{x}, t_{l}^{*}\right)}{\left[\sigma_{T}^{2}\left(\vec{x}, t_{l}^{*}\right)+\sigma_{\mathrm{om} T}^{2}\left(\vec{x}, t_{l}\right)\right]}=\frac{\sigma_{T}^{2}\left(\vec{x}, t_{l}^{*}\right) \sigma_{\mathrm{omT}}^{2}\left(\vec{x}, t_{l}\right)}{\left[\sigma_{T}^{2}\left(\vec{x}, t_{l}^{*}\right)+\sigma_{\mathrm{om} T}^{2}\left(\vec{x}, t_{l}\right)\right]} .
$$

Formulas (1)-(8) and expression (9) representing temperature are to be supplemented with the analogous formulas and the equation for salinity.

Brief information on the applied assimilation model. To assimilate the reconstructed three-dimensional fields of the temperature and salinity pseudomeasurements, a version of the numerical eddy-resolving model developed in the Marine Hydrophysical Institute (MHI) was used (its full version is presented in [16]). Here the equations of heat and salt transport-diffusion are given in the following form

$$
\begin{aligned}
& \frac{d T}{d t}=-k^{\mathrm{H}} \Delta^{2} T+\left(k^{T} T_{z}\right)_{z}-\frac{\partial I}{\partial z}+Q_{T}, \\
& \frac{d S}{d t}=-k^{\mathrm{H}} \Delta^{2} S+\left(k^{S} S_{z}\right)_{z}+Q_{S},
\end{aligned}
$$

where $\Delta^{2}$ is the bi-harmonic operator; $I(z)=\operatorname{Swr}\left[a \exp \left(-z / b_{1}\right)+(1-a) \exp \left(-z / b_{2}\right)\right]$; $S w r$ is a short-wave radiation on the sea surface; $Q_{T}, Q_{S}$ are the assimilation sources (8). The coefficients of turbulent exchange of momentum $\left(v_{V}\right)$, heat $\left(k^{T}\right)$ and salt $\left(k^{S}\right)$ down the vertical were calculated using the Philander-Pacanowski approximation [17]. 
The model horizontal resolution is $5 \times 5 \mathrm{~km}$ ( $238 \times 132$ points), 38 horizons were used over the vertical: $2.5 ; 5 ; 10 ; . . ; 30 ; 40 ; 50 ; 63 ; 75 ; 88 ; 100 ; 113 ; 125$; $150 ; \ldots ; 200 ; 250 ; 300 ; 400 ; \ldots$ and $2100 \mathrm{~m}$. In the bi-harmonic operators, the coefficients of the momentum turbulent exchange and the heat and salt turbulent diffusion were assumed to be equal to $v_{\mathrm{H}}=5 \cdot 10^{17} \mathrm{~cm}^{4} / \mathrm{s}, \mathrm{k}^{\mathrm{H}}=10^{16} \mathrm{~cm}^{4} / \mathrm{s}$, respectively. The atmospheric fields were used from the ERA-Interim reanalysis [18].

To continue comparison, let us represent the source of the simplified method of the temperature pseudo-measurements' assimilation in the following form

$$
Q_{T}\left(\vec{x}, t_{l}\right)=\frac{1}{\operatorname{REL} 1\left[1+\eta_{T}^{2}\left(z, t_{\mathrm{mec}}\right)\right.}\left[T^{\mathrm{obs}}\left(\vec{x}, t_{l}\right)-T\left(\vec{x}, t_{l}\right)\right],
$$

where $\eta_{T}{ }^{2}\left(z, t_{\text {мес }}\right)$ is the monthly average values of "the measurements errors" [19, p. 130-131] equal to the ratio of the squared RMS of the temperature pseudomeasurements to dispersion of natural variability of the measured temperature fields. The similar source is represented for salinity.

The differential equations of the MHI model [16] were supplemented with two single-type equations similar to (6) for which the following boundary conditions were used: on the basin surface, on solid lateral boundaries and on the river banks and in the straits; besides, the dispersion flows at the bottom are equal to zero. At the initial time, the values of typical dispersions were preset. The advection summands of the transport-diffusion equations of the forecast errors' dispersions were approximated using the TVD-scheme [20]. Such a scheme guaranteed calculation of positive-determined scalar functions. In the Laplace operators of both equations, the coefficient of the horizontal turbulent diffusion of the errors' dispersion was assumed to be equal to $k_{H}=10^{5} \mathrm{~cm}^{2} / \mathrm{s}$.

Selection of the relaxation parameter in the transport-diffusion equations of the forecast errors' dispersions. Typical dispersions of the temperature $\sigma_{*}^{2}\left(\vec{x}, t_{l}\right)$ and salinity $\sigma_{* S}^{2}\left(\vec{x}, t_{l}\right)$ forecast errors are assessed according to the method represented in [14]. In contrast to the above-mentioned paper, the authors of the present one used (for the same purpose) an ensemble of the temperature and salinity values resulted from calculating the sea fields for 20 years (1993-2012) based on the MHI model [16] without assimilating the measurement data. The atmospheric fields were preset by the results of the ERA-Interim reanalysis [18]. Such an approach is methodologically close to obtaining the ensemble of the model state vectors for assessing the covariations' matrix in the developed parallel algorithm of the ensemble optimal interpolation described in [21].

Let $T_{i, j, k, t_{d}}^{m}$ is a time series of the prognostic temperature three-dimensional fields reconstructed based on the results of the forecast with a 1 day resolution for the period $m$ years $[1,20]$ and the horizontal resolution $5 \times 5 \mathrm{~km}$ in the grid points of the model: $i[1,238]$ on the axis $x, j[1,132]$ on the axis $y, k[1,38]$ on the axis $z$. In this case, the yearly summed up square of the temperature deviations from the mean-time value was taken as a typical dispersion of the temperature forecast errors for each day within the conventional year $d[1,365]$ : 


$$
\sigma_{*}^{2} T_{i, j, k, t_{d}}=\frac{1}{19} \sum_{m=1}^{20}\left[T_{i, j, k, t_{d}}^{m}-\bar{T}_{i, j, k, t_{d}}\right]^{2},
$$

where the temperature mean value is calculated by the formula

$$
\bar{T}_{i, j, k, t_{d}}=\frac{1}{20} \sum_{m=1}^{20} T_{i, j, k, t_{d}}^{m} .
$$

The typical dispersion of the salinity forecast errors was assessed in a similar way.

The diagram on Fig. 1, a shows that the heightened values of the basinaveraged salinity typical dispersion are concentrated in the $100-150 \mathrm{~m}$ layer. It is known that the constant halocline and the main pycnocline lie within the 50-100 m depths [22]. The higher values of the salinity typical dispersion in the layer 100$150 \mathrm{~m}$ can be explained by the fact that the temperature and salinity profiles (model POM [23] and MHI model [16], respectively) constructed using the prognostic data are somewhat smoothed in this layer as compared to the observations.

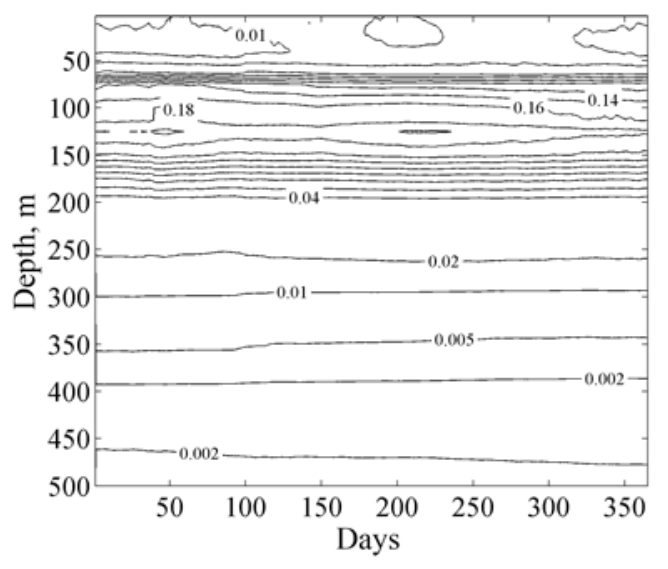

$a$
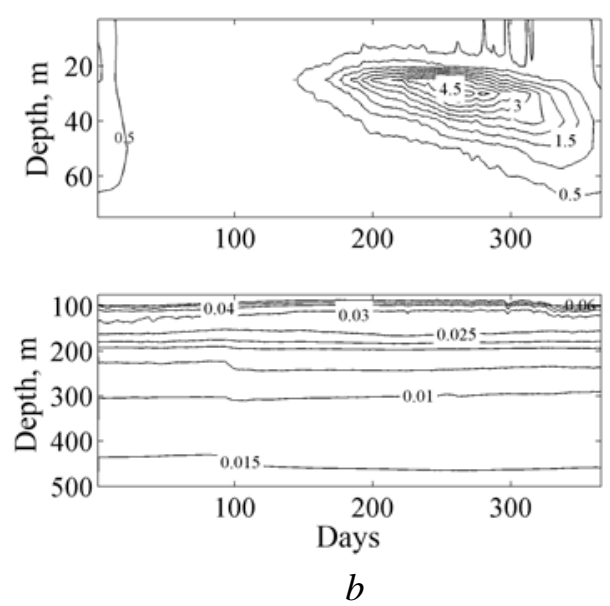

Fig. 1. Temporal variability of the mean daily values of typical dispersions of the salinity $(a)$ and temperature $(b)$ forecast errors averaged over the horizons within the $0-500 \mathrm{~m}$ layer

Distribution of the heightened (over depth and time) temperature typical dispersion values (Fig. 1, $b$ ) is explained by the features of the thermodynamic processes in the sea upper layer which are characteristic of the upper mixed layer (UML) formation, and arising of a new cold intermediate layer (CIL) and maintaining of the previously formed one. Distribution of temperature dispersions from the surface to the depth 40-60 m in January, November and December indicates formation of UML. The significantly increased dispersion is observed from May to December on the depths within CIL. It is conditioned by the following processes: formation of seasonal thermocline, deepening of the CIL upper and lower boundaries, dividing of the layer into several parts in autumn and the CIL renewal in winter. In the $100-500 \mathrm{~m}$ layer, the temperature dispersion is smaller by two orders and decreases monotonically with depth.

Spatial distribution of the salinity and temperature typical dispersions on the horizons within the $100-500 \mathrm{~m}$ layer for a specific date of a conventional year is characterized by localization of their heightened values in the central part of the sea and their reduced ones - in the region adjacent to the $500 \mathrm{~m}$ isobath. 
To choose the parameter, three prognostic model calculations for 2012 (without assimilation of the temperature and salinity pseudo-measurements) were done with simultaneous numerical solution of the equations similar to (6) at REL $=3,10$ and 15 days. The value of the relaxation parameter, at which the order of the horizontal advection and that of the source on the right-hand side of the equation similar to (6) are comparable, was chosen to carry out numerical experiments including model assimilation of the temperature and salinity pseudo-measurements. The correlation between the positions of the circulation structures and the salinity forecast errors' typical dispersion is well seen in Fig. 2, $a, c$ and $d$. The same correlation is observed between the location of the current structures and the temperature forecast errors' dispersion. The calculation results permitted to choose the relaxation parameter value equal to 10 days.
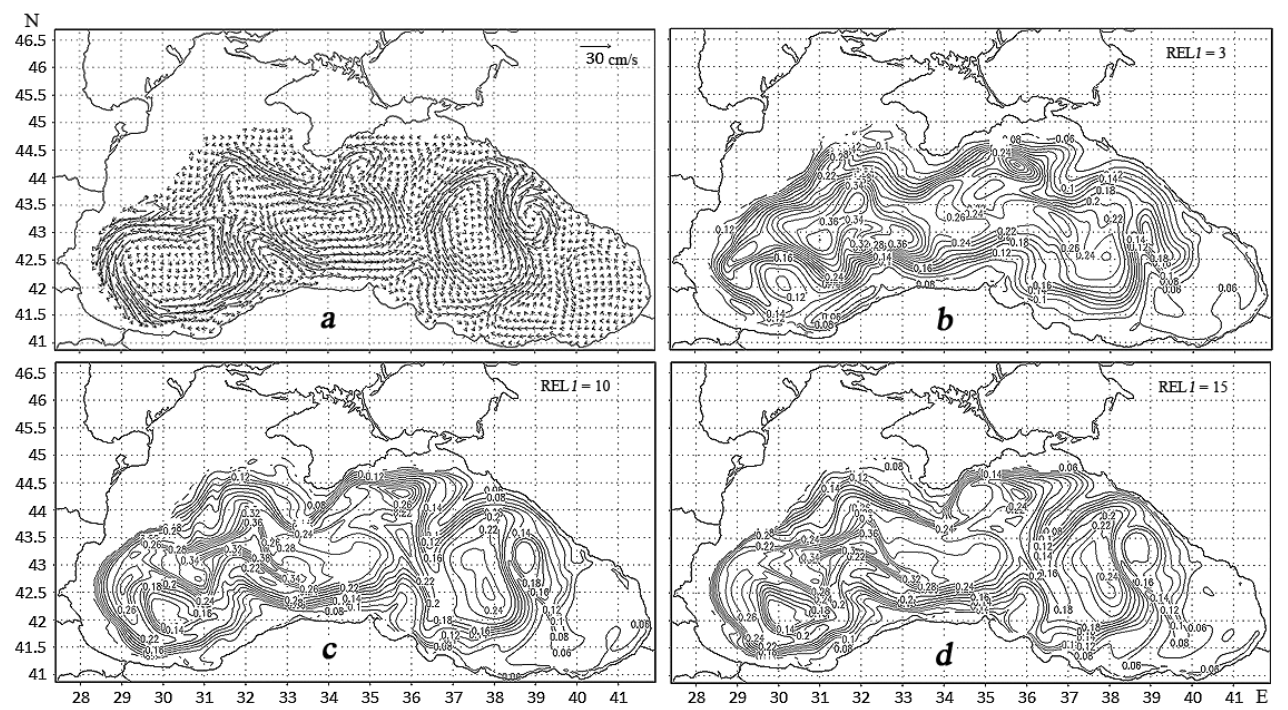

Fig. 2. Currents (a) and typical dispersion of the salinity forecast errors calculated with REL1 $=3(b)$, $10(c)$ and 15 days $(d)$ at the horizon $100 \mathrm{~m}$ on 15.09.2012.

Analysis of the results of the numerical experiments including assimilation of the temperature and salinity pseudo-measurements in the model by the method of adaptive statistics. Numerical experiments aimed at reconstruction of the Black Sea hydrophysical fields in 2012 were performed using the adaptive statistics method. The initial fields (temperature, salt, current velocity vector components and sea level for 01.01.2012) from the reanalysis for 1993-2012 were used along with the model assimilation of the altimetry derived temperature and salinity profiles of a zero sea level gradation [24]. The data of the temperature and salinity pseudo-measurements were assimilated in equations (10) and (11) at each time step $t_{l}=l \Delta t$, where $\Delta t$ is the 5 min. time step in the numerical model and $l=1,2, \ldots$. The model dispersions of the temperature and salinity forecast errors were also corrected according to the relations similar to (9) at each time step. Dispersions of the errors $\sigma_{\mathrm{owT}}^{2}\left(\vec{x}, t_{l}\right)$ and $\sigma_{\mathrm{owS}}^{2}\left(\vec{x}, t_{l}\right)$ arising in reconstructing pseudo-measurements on the horizons within the $100-500 \mathrm{~m}$ layer were equal to the averaged over a month square RMS of the reconstructed temperature and salinity relative to the Argo buoys' measurements. 
Choice of the relaxation parameter in the sources of the heat and salt transport-diffusion equations. To select the relaxation parameter, five reanalyses for 2012 were carried out with REL1 = 3, 6, 12, 24 and 36 hours. The parameter optimal value was chosen by analyzing RMS (estimated for 2012) of the model temperature and salinity values and the measured ones on each horizon up to $1000 \mathrm{~m}$.

Table 1

Root-mean-square (RMS) of the model-reconstructed salinity fields: I - using the method of adaptive statistics, II - using the simplified method, III - in the prognostic calculation; the root of the measured $(\sigma)$ salinity values' dispersion over the horizons for 2012

\begin{tabular}{|c|c|c|c|c|c|c|c|c|}
\hline \multirow{4}{*}{$\begin{array}{l}\text { Horizon, } \\
\mathrm{m}\end{array}$} & \multicolumn{7}{|c|}{ RMS, \% } & \multirow{4}{*}{$\sigma, \%$} \\
\hline & \multirow{2}{*}{\multicolumn{5}{|c|}{$\frac{\text { I }}{\text { REL1 }}$}} & II & \multirow{3}{*}{ III } & \\
\hline & & & & & & REL1 & & \\
\hline & $3 \mathrm{hr}$ & $6 \mathrm{hr}$ & $12 \mathrm{hr}$ & $24 \mathrm{hr}$ & $36 \mathrm{hr}$ & $12 \mathrm{hr}$ & & \\
\hline 3 & 0.135 & 0.154 & 0.137 & 0.140 & 0.132 & 0.159 & 0.141 & 0.170 \\
\hline 5 & 0.201 & 0.199 & 0.194 & 0.196 & 0.189 & 0.200 & 0.214 & 0.252 \\
\hline 10 & 0.171 & 0.169 & 0.169 & 0.164 & 0.163 & 0.170 & 0.186 & 0.205 \\
\hline 15 & 0.148 & 0.143 & 0.143 & 0.135 & 0.136 & 0.147 & 0.156 & 0.178 \\
\hline 20 & 0.128 & 0.120 & 0.118 & 0.109 & 0.110 & 0.126 & 0.137 & 0.143 \\
\hline 25 & 0.134 & 0.124 & 0.120 & 0.113 & 0.115 & 0.129 & 0.133 & 0.125 \\
\hline 30 & 0.141 & 0.131 & 0.128 & 0.122 & 0.124 & 0.133 & 0.139 & 0.117 \\
\hline 40 & 0.201 & 0.191 & 0.190 & 0.187 & 0.184 & 0.201 & 0.199 & 0.205 \\
\hline 50 & 0.388 & 0.368 & 0.367 & 0.353 & 0.339 & 0.404 & 0.343 & 0.417 \\
\hline 63 & 0.625 & 0.589 & 0.582 & 0.537 & 0.511 & 0.660 & 0.582 & 0.630 \\
\hline 75 & 0.493 & 0.457 & 0.463 & 0.455 & 0.446 & 0.575 & 0.558 & 0.707 \\
\hline 88 & 0.522 & 0.490 & 0.496 & 0.491 & 0.494 & 0.615 & 0.580 & 0.696 \\
\hline 100 & 0.398 & 0.394 & 0.400 & 0.436 & 0.442 & 0.408 & 0.534 & 0.617 \\
\hline 113 & 0.343 & 0.340 & 0.331 & 0.362 & 0.369 & 0.348 & 0.459 & 0.504 \\
\hline 125 & 0.272 & 0.268 & 0.259 & 0.285 & 0.293 & 0.279 & 0.380 & 0.414 \\
\hline 150 & 0.164 & 0.159 & 0.153 & 0.158 & 0.161 & 0.169 & 0.248 & 0.249 \\
\hline 175 & 0.112 & 0.108 & 0.104 & 0.105 & 0.105 & 0.114 & 0.166 & 0.161 \\
\hline 200 & 0.092 & 0.089 & 0.086 & 0.087 & 0.087 & 0.093 & 0.112 & 0.121 \\
\hline 250 & 0.061 & 0.060 & 0.057 & 0.058 & 0.058 & 0.061 & 0.082 & 0.073 \\
\hline 300 & 0.041 & 0.041 & 0.038 & 0.039 & 0.038 & 0.041 & 0.051 & 0.048 \\
\hline 400 & 0.024 & 0.024 & 0.023 & 0.023 & 0.022 & 0.024 & 0.031 & 0.027 \\
\hline 500 & 0.017 & 0.019 & 0.016 & 0.021 & 0.020 & 0.017 & 0.023 & 0.017 \\
\hline
\end{tabular}

It follows from Table 1 that the salinity fields in the seasonal halocline layer ( 0 $30 \mathrm{~m}$ ) in all the calculations, except for the first one, are reconstructed quite satisfactorily. Significant differences between the model and the measured fields are observed within the constant halocline (50-125 m). The RMS values, having been assessed over the horizons within the 100-500 m layer and compared, and with the root of dispersion of natural variability of the measured salinity fields taken into account, permit to conclude that the value REL1 $=12 \mathrm{hr}$ is more preferable.

The values of the temperature fields' RMS are the highest (Table 2) at the depth $20 \mathrm{~m}$ corresponding to the seasonal thermocline. It is difficult to determine unambiguously the optimum value of the relaxation parameter based on the results of estimat- 
ing the temperature fields' RMS in the 100-500 m layer. Reliability of reconstruction and seasonal variability of the hydrophysical fields in the layer $0-88 \mathrm{~m}$ are conditioned mainly by quality both of the model and the fields of atmospheric forcing. The RMS estimates resulted from the reanalyses and from the prognostic calculation indicate inaccurate reconstruction of thermodynamics of the sea upper layer. Since in the equation of the seawater state the basic contribution is done by salinity, let us accept the value REL1 = $12 \mathrm{hr}$ for the heat transport-diffusion equation. The results of the reanalysis carried out with this value of the relaxation coefficient were used for subsequent study of the reconstructed hydrophysical and statistical fields.

Table 2

Root-mean-square (RMS) of the model-reconstructed temperature fields: I - using the method of adaptive statistics, II - using the simplified method, III - in the prognostic calculation; the root of the measured ( $\sigma$ ) temperature values' dispersion over the horizons for 2012

\begin{tabular}{|c|c|c|c|c|c|c|c|c|}
\hline \multirow{4}{*}{$\begin{array}{c}\text { Horizon, } \\
\text { m }\end{array}$} & \multicolumn{7}{|c|}{$\mathrm{RMS},{ }^{\circ} \mathrm{C}$} & \multirow{4}{*}{$\sigma,{ }^{\circ} \mathrm{C}$} \\
\hline & \multirow{2}{*}{\multicolumn{5}{|c|}{$\frac{\mathrm{I}}{\text { REL1 }}$}} & II & \multirow{3}{*}{ III } & \\
\hline & & & & & & REL1 & & \\
\hline & 3hr & $6 \mathrm{hr}$ & $12 \mathrm{hr}$ & $24 \mathrm{hr}$ & $36 \mathrm{hr}$ & $12 \mathrm{hr}$ & & \\
\hline 3 & 1.860 & 1.898 & 1.916 & 1.957 & 1.973 & 1.917 & 1.969 & 5.330 \\
\hline 5 & 2.360 & 2.365 & 2.409 & 2.444 & 2.462 & 2.385 & 2.431 & 6.337 \\
\hline 10 & 2.436 & 2.442 & 2.473 & 2.486 & 2.500 & 2.447 & 2.456 & 6.452 \\
\hline 15 & 3.786 & 3.765 & 3.809 & 3.782 & 3.774 & 3.820 & 3.768 & 5.503 \\
\hline 20 & 5.129 & 5.073 & 5.116 & 5.064 & 5.050 & 5.173 & 5.090 & 4.561 \\
\hline 25 & 4.555 & 4.454 & 4.559 & 4.448 & 4.418 & 4.640 & 4.563 & 3.758 \\
\hline 30 & 2.979 & 2.906 & 3.033 & 2.985 & 2.948 & 3.108 & 2.987 & 2.394 \\
\hline 40 & 1.928 & 1.919 & 1.994 & 1.954 & 1.949 & 1.997 & 1.884 & $0, .946$ \\
\hline 50 & 1.171 & 1.197 & 1.233 & 1.219 & 1.214 & 1.212 & 1.117 & 0.669 \\
\hline 63 & 0.726 & 0.768 & 0.770 & 0.773 & 0.764 & 0.763 & 0.739 & 0.655 \\
\hline 75 & 0.497 & 0.522 & 0.544 & 0.558 & 0.556 & 0.508 & 0.615 & 0.624 \\
\hline 88 & 0.347 & 0.368 & 0.390 & 0.413 & 0.420 & 0.350 & 0.508 & 0.483 \\
\hline 100 & 0.258 & 0.251 & 0.249 & 0.267 & 0.273 & 0.291 & 0.363 & 0.321 \\
\hline 113 & 0.197 & 0.182 & 0.168 & 0.165 & 0.165 & 0.208 & 0.226 & 0.185 \\
\hline 125 & 0.111 & 0.104 & 0.101 & 0.099 & 0.101 & 0.117 & 0.144 & 0.121 \\
\hline 150 & 0.049 & 0.049 & 0.049 & 0.050 & 0.051 & 0.050 & 0.095 & 0.065 \\
\hline 175 & 0.035 & 0.035 & 0.034 & 0.035 & 0.035 & 0.036 & 0.076 & 0.045 \\
\hline 200 & 0.032 & 0.031 & 0.028 & 0.029 & 0.029 & 0.032 & 0.055 & 0.037 \\
\hline 250 & 0.022 & 0.022 & 0.022 & 0.022 & 0.022 & 0.022 & 0.033 & 0.024 \\
\hline 300 & 0.015 & 0.014 & 0.013 & 0.014 & 0.014 & 0.014 & 0.027 & 0.014 \\
\hline 400 & 0.007 & 0.007 & 0.007 & 0.007 & 0.007 & 0.007 & 0.016 & 0.006 \\
\hline 500 & 0.006 & 0.006 & 0.006 & 0.008 & 0.009 & 0.006 & 0.016 & 0.007 \\
\hline
\end{tabular}

Comparison of the actual and model dispersions of the forecast errors. The numerical experiments on the horizons within the 100-500 m layer have resulted in obtaining the model daily average dispersions of the temperature (salinity) fields' forecast errors calculated by the equations similar to (6) and corrected by the formulas similar to (9); also obtained are the dispersions of the differences (residuals) between the temperature (salinity) pseudo-measured value and the model one. It is seen in Fig. 3, $a$ that the values of the typical temperature dispersion are higher than those 44 
of the residuals which, in their turn, exceed the values of the model dispersion. At that the model dispersion varies in time rather smoothly. Its fields correspond to the sea dynamics. Let us pay attention to the values and seasonal variation of the residuals characterizing actual deviations of model temperature from the pseudomeasurements. It is evident that in January - February and September - December, the values of the residuals' dispersions are close to those of the model dispersion. The values of the considered statistical characteristics on the horizon $100 \mathrm{~m}$ are slightly higher than on $113 \mathrm{~m}$, whereas seasonal variation of the residuals' dispersion is the same. However, its values exceed those of the model dispersion. The values of all the statistical characteristics on the horizons within the 100-500 m layer decrease with depth. The residuals' dispersion on the horizons within the 150-500 m layer becomes smaller than the model one.
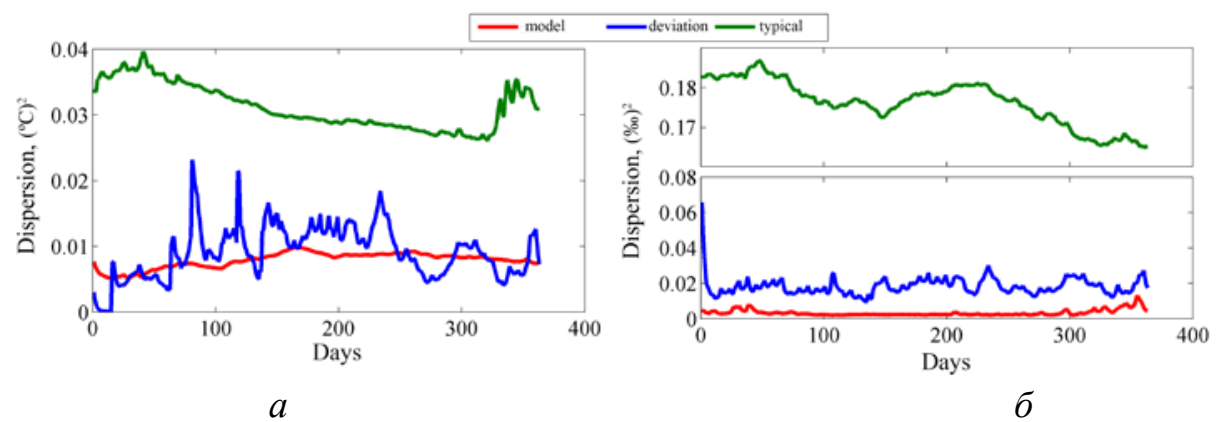

Fig. 3. Seasonal variability of the horizon average typical and model dispersions of the forecast errors and the average dispersion of the temperature $(a)$ and salinity $(b)$ residuals at the horizon $113 \mathrm{~m}$

The values of the typical salinity dispersion are higher than those of the model and residuals' ones (Fig. 3, b). The residuals' dispersion exceeds the model one on the horizons 100-200 m, although approaches it with the depth increase. The residuals' dispersion becomes smaller than the model one within the layer 250-500 m. Excess of the values of the salinity residuals' dispersions over the model dispersion values on a larger number of horizons, as compared to temperature, is conditioned by the high RMS values of the salinity pseudo-measurements.

Comparison of the reconstructed structures of the sea hydrophysical fields. Let us compare the maps of currents and dispersions of the typical and model forecast errors (Fig. 4). It is seen in Fig. 4, $a$ that the structures with smaller values of typical dispersion correspond to anticyclones, and those with higher values - to the cyclonic gyres. The same correspondence is observed between the model dispersion values and circulation structures on the horizon $100 \mathrm{~m}$ (Fig. 4, b). Fig. 5, $a$ demonstrates that the smaller modules of the salinity and temperature residuals are characteristic of the cyclonic gyres, whereas the larger ones - of the anticyclones and periphery. The noted features of the applied method provide mutual agreement between the statistical parameters and the reconstructed hydrophysical fields of the sea. The heightened values of the model dispersion in the cyclonic gyres and the cyclones mean higher significance of the data in the model (the sources similar to (8)), while the decreased dispersion values in the anticyclones and over the basin periphery - stronger influence of the model in reconstructing the hydrological fields. 

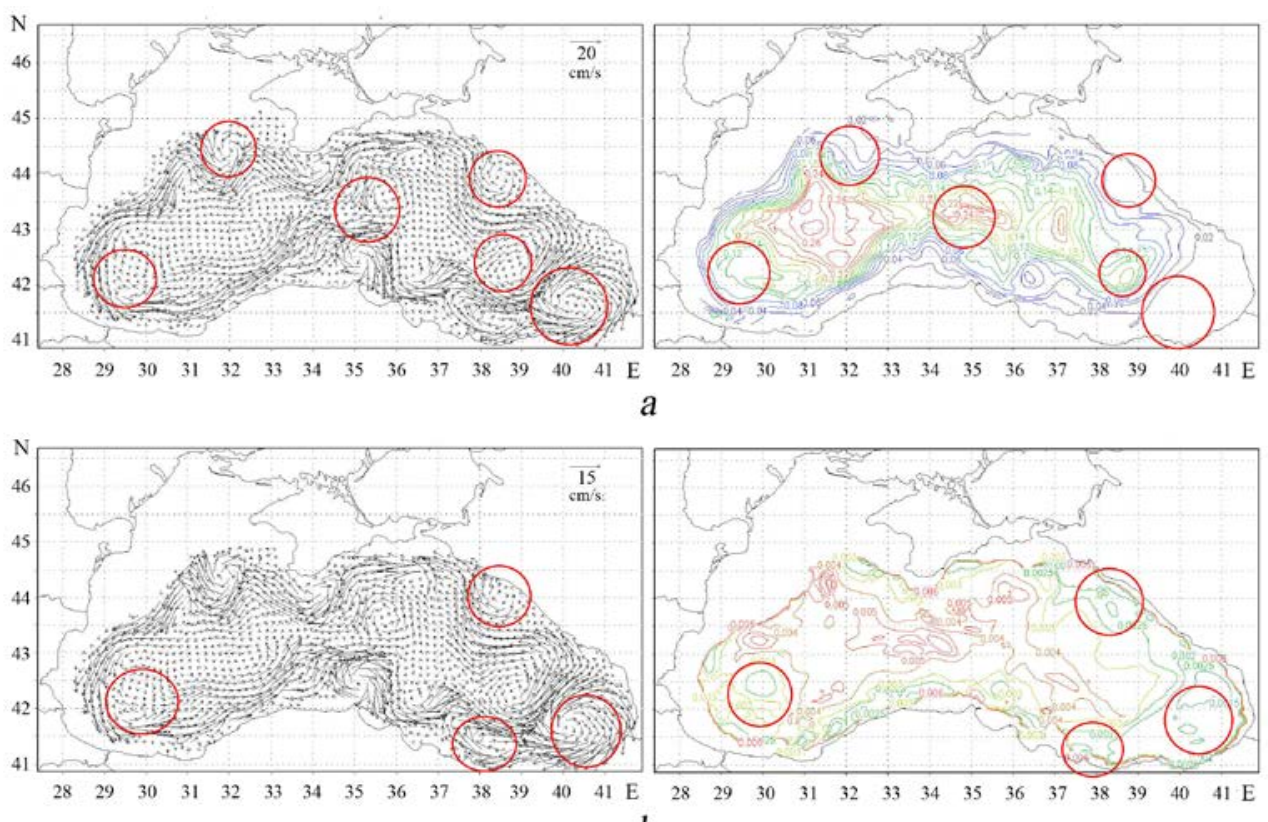

$b$

Fig. 4. Currents and typical dispersion of the salinity forecast errors at the horizon $75 \mathrm{~m} \mathrm{(a)}$; currents and model dispersion of the salinity forecast errors at the horizon $100 \mathrm{~m}(b)$ on 15.07.2012
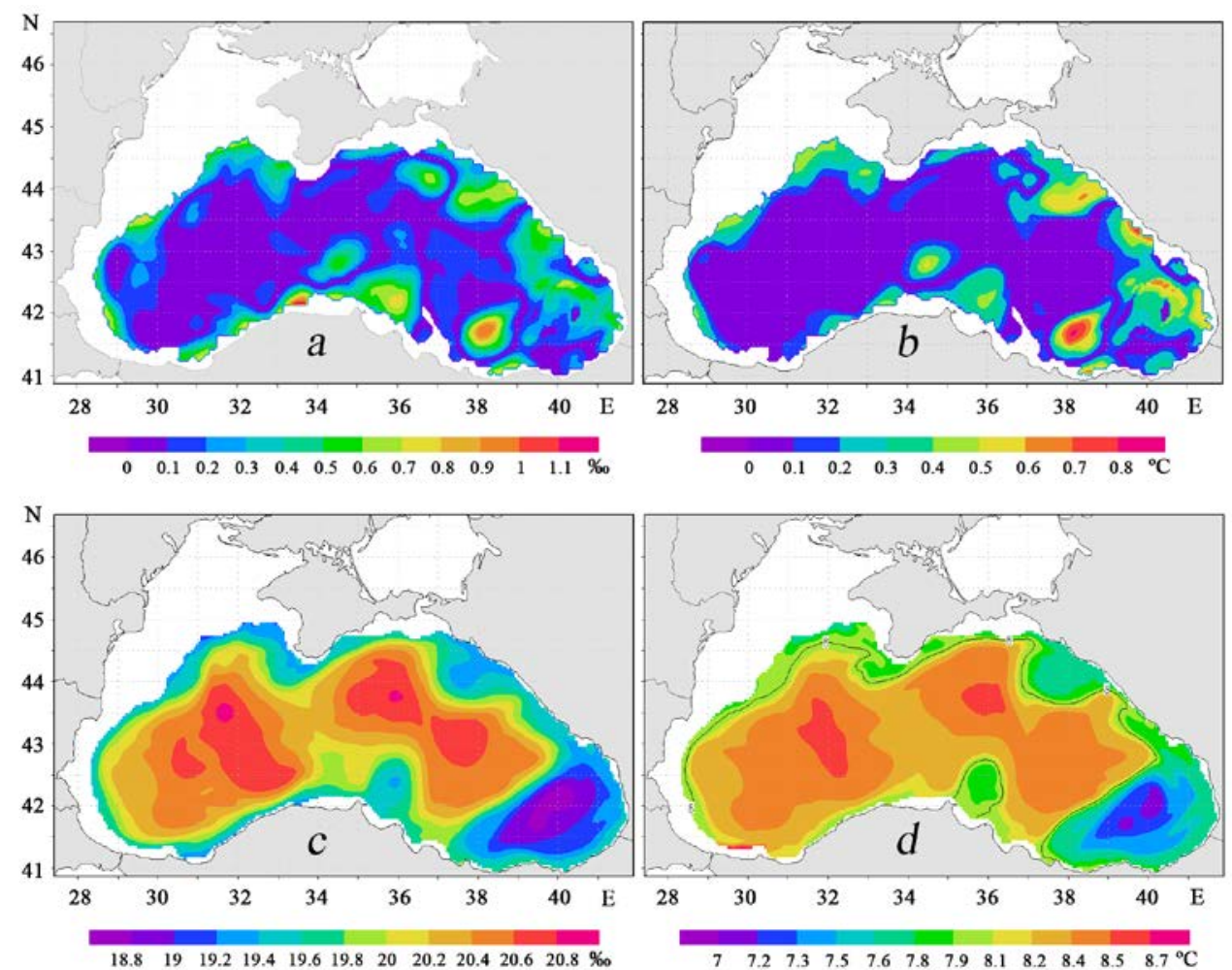

Fig. 5. Distribution of the salinity residuals' module (a), the residuals' module of temperature (c), salinity $(b)$ and temperature $(d)$ at the horizon 100 m on 15.09.2012 
Application of the adaptive statistics method for assimilating the temperature and salinity pseudo-measurements in the reanalysis for 2012 permitted to reconstruct some meso-scale eddies in the current fields, though these vortices were not obtained as a result of the prognostic calculation and at applying the simplified assimilation method. It is observed in three regions of the sea (Fig. 6). On the current map (Fig. 6, b) in its southwestern part, the cyclonic-anticyclonic vortices' dipole system is distinctly pronounced; it is also seen on the sea level map (Fig. 6, $a$ ). On the circulation map resulted from the reanalysis including the model assimilation of pseudo-measurements by the simplified method, instead of the vortices' dipole system there is one cyclonic vortex (Fig. 6, d). Difference between the results of the currents' calculations obtained by two methods is noticeable in the vicinity of the Sevastopol anticyclone. The current system here consists of three vortices (Fig. 6, b) - two anticyclones and a cyclone - that is closer to the salinity field (Fig. 6, c) and sea level (Fig. 6, $a$ ) structures. Finally, the level local lowering in the northeast curve of the Rim Current (Fig. 6, $a$ ) indicates a cyclonic vortex which is more clearly pronounced in Fig. 6, $b$ as compared to Fig. 6, $d$.
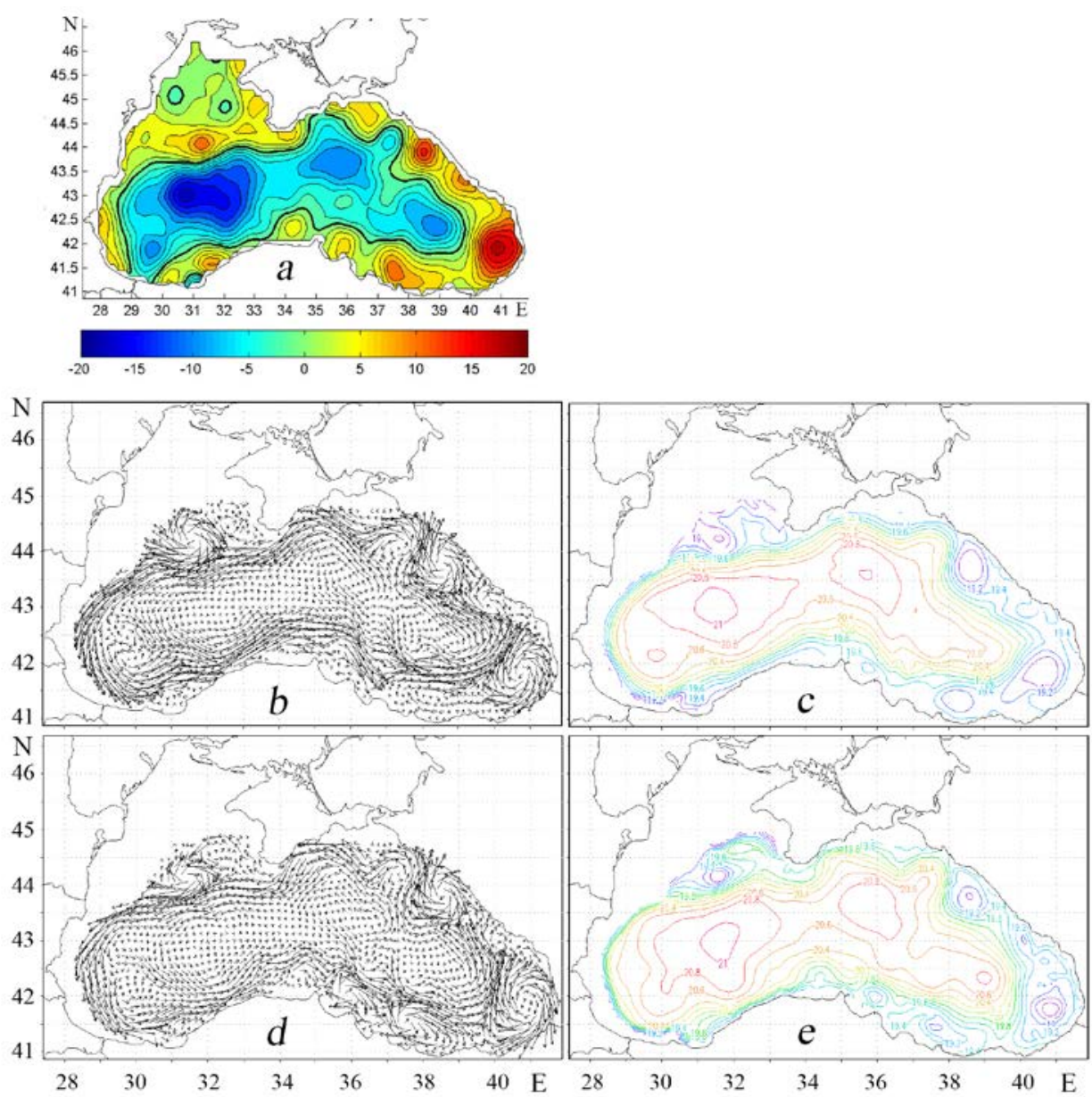

Fig. 6. Altimetry-derived sea level (a) currents and salinity at the horizon $100 \mathrm{~m}$ reconstructed using the method of adaptive statistics $(b, c)$ and the simplified method $(d, e)$ for 9.05 .2012

PHYSICAL OCEANOGRAPHY VOL. 25, ISS. 1 (2018) 
The sea level is an important hydrodynamic function conditioning the surface geostrophic currents. Comparison of the sea level calculated by the method of adaptive statistics, using the altimetry data and in the forecast is shown in Fig. 7. It is seen that location of the cyclonic gyres and the main anticyclones in the reanalysis and in the altimetry sea level is similar since the temperature and salinity pseudo-measurements are bound to the altimetry level [15]. At the same time localization of the above-mentioned structures in the prognostic calculation is different. Note that the drop of the altimetry-derived level is much larger $(32 \mathrm{~cm})$ than that reconstructed in the assimilation model $(25 \mathrm{~cm})$. The reason of the small level drop and the vortices' weak intensity consists in insufficient accuracy of modeling thermodynamics of the sea upper layer $(0-100 \mathrm{~m})$, since the temperature and salinity pseudo-measurements are not assimilated in this layer due to their absence [15], and formation of the thermohaline fields' structure is mainly conditioned by quality of the model and the atmospheric forcing fields.
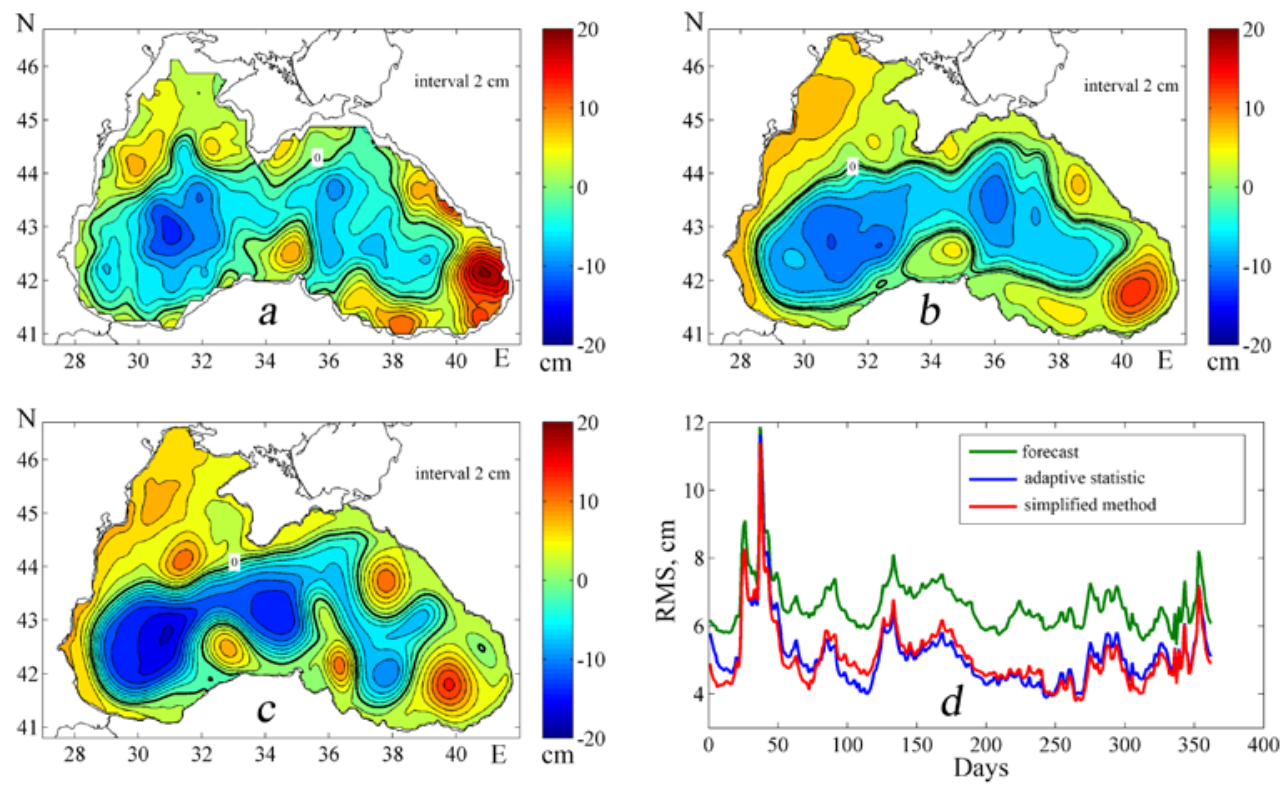

Fig. 7. Sea level reconstructed using the altimetry data (a), the method of adaptive statistics $(b)$ and the prognostic calculation (c) for 26.06.2012 and the RMS seasonal variability of the reconstructed level (relative to the altimetry one) in three variants $(d)$

The dynamic sea level fields calculated for each day using the data on level anomalies [25] permitted to assess RMS of the reconstructed sea level (relative to the altimetry-derived one) in three variants of the model simulations. It is seen in Fig. 7, $d$ that the RMS values of the level in all the variants are quite high; at that the highest ones are in the prognostic calculation. The values of RMS are close in the variants implying assimilation of the temperature and salinity pseudomeasurements both by the simplified method and the method of adaptive statistics. In order to specify the temperature and salinity fields reconstructed by the reanalysis, it is necessary to assimilate in the model jointly the altimetry-derived sea level and the three-dimensional temperature and salinity pseudo-measurements in the 100-500 m layer. 
Conclusions. Specification of the previously proposed method of adaptive statistics consists in applying new estimates of typical dispersions of the temperature and salinity forecast errors, and also in adapting the model errors' dispersions to the water circulation in the basin. The method was approved by reconstructing the Black Sea hydrophysical fields in the retrospective analysis for 2012 including the model assimilation of the three-dimensional fields of the temperature and salinity pseudo-measurements within the 100-500 m layer of the deep-sea region bounded by the $500 \mathrm{~m}$ isobath [15].

Application of the method of adaptive statistics provided agreement between the hydrophysical fields and the statistical parameters. Spatial distribution of the model forecast errors' dispersion is characterized by localization of its heightened values in the cyclonic gyres and cyclones, and the decreased ones - in the anticyclones. The modules of differences (residuals) between the pseudo-measurements and the model values of temperature and salinity are smaller in the structures with positive vorticity and larger - in those with negative one.

The method of adaptive statistics provided higher accuracy in reconstructing the meso-scale vortex structures in the current fields than that of the simplified assimilation. The synoptic vortices' locations on the maps of the sea level reconstructed in the reanalysis and using the altimetry data are similar. The diurnal RMS of the model level, as compared to the altimetry derived one, is smaller than that calculated in the forecast; and during the period March - September, it is lower than the RMS obtained from the pseudo-measurements' assimilation carried out by the simplified assimilation method.

Comparison of the sea fields reconstructed in the reanalysis and the Argo measurements made it possible to determine the maximum values of the annual average RMS: for salinity - in the halocline $(63 \mathrm{~m})$, for temperature - in the upper layer $(0-100 \mathrm{~m})$. To increase accuracy of reconstructing hydrophysical fields, it is necessary to assimilate the data in the $0-100 \mathrm{~m}$ layer.

\section{REFERENCES}

1. Agoshkov, V.I., Parmuzin, E.I. and Shutyaev, V.P., 2013. Observational Data Assimilation in the Problem of Black Sea Circulation and Sensitivity Analysis of its Solution. Izvestiya. Atmospheric and Oceanic Physics, [e-journal] 49(6), pp. 592-602. doi:10.1134/S0001433813060029

2. Gejadze, I.Yu., Le Dimet, F.-X. and Shutyaev, V., 2008. On Analysis Error Covariances in Variational Data Assimilation. SIAM J. Sci. Comput., [e-journal] 30(4), pp. 1847-1874. doi:10.1137/07068744X

3. Zalesny, V.B. and Ivchenko, V.O., 2015. Simulating Large-Scale Circulation in Seas and Oceans. Izvestiya. Atmospheric and Ocean Physics, [e-journal] 51(3), pp. 259-271. doi:10.1134/S0001433815030135

4. Jazwinski, A.H., 1970. Stochastic Processes and Filtering Theory. New York: Academic Press, 376 p.

5. Sakava, Y., 1972. Optimal Filtering in Linear Distributed-Parameter Systems. International Journal of Control, [e-journal] 16(1), pp. 115-127. https://doi.org/10.1080/00207177208932247

6. Belyaev, K.P., Tanajura, C.A.S. and Tuchkova, N.P., 2012. Comparison of Methods for Argo Drifters Data Assimilation into a Hydrodynamical Model of the Ocean. Oceanology, [e-journal] 52(5), pp. 593-603. doi:10.1134/S0001437012050025 
7. Kaurkin, M.N., Ibrayev, R.A. and Belyaev, K.P., 2016. Data Assimilation in the Ocean Circulation Model of High Spatial Resolution Using the Methods of Parallel Programming. Russ. Meteorol. Hydrol., [e-journal] 41(7), pp. 479-486. https://doi.org/10.3103/S1068373916070050

8. Dorofeev, V.L. and Sukhikh, L.I., 2016. Analysis of Variability of the Black Sea Hydrophysical Fields in 1993-2012 Based on the Reanalysis Results. Physical Oceanography, [e-journal] (1), pp. 33-47. doi:10.22449/1573-160X-2016-1-33-47

9. Evensen, G., 2003. The Ensemble Kalman Filter: Theoretical Formulation and Practical Implementation. Ocean Dyn., [e-journal] 53(4), pp. 343-367. doi:10.1007/s10236-003-0036-9

10. Counillon, F. and Bertino, L., 2009. High-Resolution Ensemble Forecasting for the Gulf of Mexico Eddies and Fronts. Ocean Dyn., [e-journal] 59(1), pp. 83-95. doi:10.1007/s10236008-0167-0

11. Klimova, E.G., 2001. Model’ Rascheta Kovariatsiy Oshibok Prognoza v Algoritme Fil'tra Kalmana, Osnovannaya Na Polnykh Uravneniyakh [A Model for Calculating the Covariance of Forecast Errors in the Kalman Filter Algorithm, Based on the Complete Equations]. Meteorologiya i Gidrologiya, (11), pp. 11-21 (in Russian).

12. Mizyuk, A.I., 2009. Osobennosti Realizatsii Algoritma Adaptivnoy Statistiki v $\sigma$-Koordinatnoy Modeli v Zadache Vosstanovleniya Gidrofizicheskikh Poley Chernogo Moray [Realization Features of the Adaptive Statistics Algorithm in a $\sigma$-Coordinate Model for Problem of the Reconstruction of the Black Sea Hydrophysical Fields]. In: MHI, 2009. Ekologicheskaya Bezopasnost' Pribrezhnoy i Shel'fovoy Zon i Kompleksnoe Ispol'zovanie Resursov Shel'fa [Ecological Safety of Coastal and Shelf Zones and Comprehensive Use of Shelf Resources]. Sevastopol: ECOSI-Gidrofizika. Iss. 18, pp. 180-192 (in Russian).

13. Knysh, V.V., Demyshev, S.G., Inyushina, N.V. and Korotaev, G.K., 2008. Assimilation of Climatic Hydrological Data in a Black-Sea Model Based on the Algorithm of Adaptive Statistics of Prognostic Errors. Physical Oceanography, [e-journal] 18(1), pp. 14-24. doi:10.1007/s11110008-9006-6

14. Mizyuk, A.I., 2014. Reanaliz Gidrofizicheskikh Poley Chernogo Morya na Osnove Assimilyatsii Dannykh Izmereniy Temperatury i Solenosti v z-Koordinatnoy Modeli [Reanalysis of the Black Sea Hydrophysical Fields Based on Temperature and Salinity Measurement Data Assimilation in the z-Coordinate Model]. Morskoy Gidrofizicheskiy Zhurnal, (3), pp. 30-47 (in Russian).

15. Korotaev, G.K., Lishaev, P.N. and Knysh, V.V., 2016. Reconstruction of the ThreeDimensional Salinity and Temperature Fields of the Black Sea on the Basis of Satellite Altimetry Measurements. Izvestiya, Atmospheric and Oceanic Physics, [e-journal] 52 (9), pp. 961-973. doi:10.1134/S0001433816090152

16. Lishaev, P.N., Korotaev, G.K., Knysh, V.V., Mizyuk, A.I. and Dymova, O.A., 2014. Vosstanovlenie Sinopticheskoy Izmenchivosti Gidrofizicheskikh Poley Chernogo Morya na Osnove Reanaliza za 1980-1993 Gody [Reproduction of Synoptic Variability of the Black Sea Hydrophysical Fields Based on Reanalysis for 1980-1993]. Morskoy Gidrofizicheskiy Zhurnal, (5), pp.49-68 (in Russian).

17. Pacanowsci, R.C. and Philander, S.G.H., 1981. Parameterization of Vertical Mixing in Numerical Models of Tropical Oceans. J. Phys. Oceanogr., [e-journal] 11(11), pp. 1443-1451. https://doi.org/10.1175/1520-0485(1981)011<1443:POVMIN>2.0.CO;2

18. Berrisford, P., Dee, D., Fielding, K., Fuentes, M., Kållberg, P., Kobayashi, S. and Uppala, S., 2009. The ERA-Interim Archive. Version 1.0. Berkshire: ECMWF, 16 p. Available at: https://www.ecmwf.int/sites/default/files/elibrary/2009/8173-era-interim-archive.pdf [Accessed: 18.08.2017].

19. Gandin, L.S. and Kagan, R.L., 1976. Statisticheskie Metody Interpretatsii Meteorologicheskikh Dannykh [Statistical Methods for the Interpretation of Meteorological Data]. Leningrad: Gidrometeoizdat, 357 p. (in Russian).

20. Pietrzak, J., 1998. The Use of TVD Limiters for Forward-in-Time Upstream-Biased Advection Schemes in Ocean Modeling. Mon. Wea. Rev., [e-journal] 126(3), pp. 812-830. https://doi.org/10.1175/1520-0493(1998)126<0812:TUOTLF>2.0.CO;2 
21. Kaurkin, M.N., Ibrayev, R.A. and Belyaev, K.P., 2016. ARGO Data Assimilation into the Ocean Dynamics Model with High Spatial Resolution Using Ensemble Optimal Interpolation (EnOI). Oceanology [e-journal], 56(6), pp. 774-781. https://doi.org/10.1134/S0001437016060059

22. Ivanov, V.A. and Belokopytov, V.N., 2011. Okeanographiya Chernogo Morya [Oceanography of the Black Sea]. Sevastopol: ECOSI-Gidrofizika, 212 p. (in Russian).

23. Ratner, Yu.B., Kubryakov, A.I., Kholod, A.L., Bayankina, T.M. and Ivanchik, M.V., 2014. Ispol'zovanie Dannykh Izmereniy s Dreyfuyushchikh Buev SVP-DTC i Argo dlya Validatsii Rezul'tatov Prognoza Temperatury Vody v Pribrezhnoy Oblasti Chernogo Morya [Application SVP-BTC and Argo Drifters' Measurement Data for Validating the Results of Seawater Temperature in the Black Sea Coastal Zone]. Morskoy Gidrofizicheskiy Zhurnal, (5), pp. 3348 (in Russian).

24. Korotaev, G.K., Sarkisyan, A.S., Knysh, V.V. and Lishaev, P.N., 2016. Reanalysis of Seasonal and Interannual Variability of Black Sea Fields for 1993-2012. Izvestiya. Atmos. Ocean. Phys., [e-journal] 52(4), pp. 418-430, doi:10.1134/S0001433816040071

25. $\mathrm{AVISO}^{+}$- Satellite Altimetry Data. [online] Available at: http://www.aviso.oceanobs.com [Accessed: 20.08.2017].

About the authors:

Gennady K. Korotaev - Scientific Supervisor of FSBSI MHI (Sevastopol, Russian Federation), Head of the Department of the Oceanic Processes Dynamics, Corresponding Member of RAS, Dr.Sci. (Phys.-Math.), Professor, ResearcherID: K-3408-2017, gkorotaev@gmail.com.

Vasily V. Knysh - Senior Researcher, Department of the Oceanic Processes Dynamics, FSBSI MHI (Sevastopol, Russian Federation), Dr.Sci. (Phys.-Math.), Professor, ResearcherID: B-36032018, vasily.knysh@mhi-ras.ru.

Pavel N. Lishaev - Junior Researcher, Department of the Oceanic Processes Dynamics, FSBSI MHI (Sevastopol, Russia), Scopus Author ID: 57193071072, pavel.lishaev@mhi-ras.ru.

Sergei G. Demyshev - Head of the Wave Theory Department, FSBSI MHI (Sevastopol, Russian Federation), Dr.Sci. (Phys.-Math.), ORCID ID: 0000-0002-5405-2282.

\section{Contribution of the co-authors:}

Genady K. Korotaev - participation in correcting the right-hand part of the differential equations of the temperature and salinity forecast errors' dispersions; advisory support; analysis and generalization of the research data; revising the paper.

Vasily V. Knysh - development of the adaptive statistics method for assimilating the temperature and salinity pseudo-measurements in the model in the problem of the Black Sea hydrophysical fields' reanalysis; analysis of the results of numerical experiments; preparation of the paper primary text.

Pavel N. Lishaev - computer implementation of the adaptive statistics method; numerical calculations; validation of the method; preparation of the graphic materials (diagrams, tables, graphs and maps).

Sergei G. Demyshev - advisory assistance in using the numerical eddy-resolving model; participation in approximating advection summands in the differential equations of the forecast errors' dispersions using the TVD-scheme.

All authors have read and approved the final manuscript.

The authors declare that they have no conflict of interest. 